\title{
Protection of Atlantic salmon Salmo salar against infectious pancreatic necrosis after DNA vaccination
}

\author{
Aase B. Mikalsen ${ }^{1}$, Jacob Torgersen ${ }^{2}$, Peter Aleström ${ }^{2}$, Anne-Lill Hellemann ${ }^{3}$, \\ Erling-Olaf Koppang ${ }^{3}$, Espen Rimstad ${ }^{1, *}$
}

\author{
${ }^{1}$ Department of Food Safety and Infection Biology, and ${ }^{2}$ Department of Basic Sciences and Aquatic Medicine, Norwegian \\ School of Veterinary Science, PO Box 8146 Dep, 0033 Oslo, Norway \\ ${ }^{3}$ GenoMar asa, Oslo Research Park, Gaustadalléen 21, 0349 Oslo, Norway
}

\begin{abstract}
Although vaccines against infectious pancreatic necrosis (IPN) based on inactivated virus or recombinant structural viral proteins are commercially available, the protection is not complete and the disease is still a problem for the Atlantic salmon Salmo salar farming industry. In the present study, 5 different plasmids that expressed whole or parts of the large open reading frames (ORF) of Segment A of the IPN virus (IPNV) were constructed. The plasmids were shown to express proteins in cell cultures and in zebrafish Danio rerio in vivo. The specificities of the expressed proteins were confirmed by staining with IPNV-specific monoclonal antibodies (MAb) The plasmids were then used alone or in different combinations to vaccinate groups of Atlantic salmon, which subsequently were challenged in an experimental assay for IPN. A high level of protection was induced only by the plasmid combination that contained a plasmid expressing all the large ORF polyprotein.
\end{abstract}

KEY WORDS: DNA-vaccination · Salmo salar · Infectious pancreatic necrosis

\section{INTRODUCTION}

Infectious pancreatic necrosis (IPN) was originally observed as an important cause of mortality in hatcheryreared salmonid fish fry (Wolf et al. 1960). The disease was originally found to occur in fishes less than $5 \mathrm{~g}$ in size. However, in farmed Atlantic salmon Salmo salar, the disease is frequently observed in larger fish, particularly in connection with smoltification and transfer to seawater.

Shedding of the etiological agent, IPN virus (IPNV) in faeces and sexual products from diseased as well as non-symptomatic carrier fishes is important for perpetuating the infection (Wolf et al. 1963, Frantsi \& Savan 1971). The digestive tract is considered to be the main entry site for IPNV, but the gills may also function as port of entry (Yamamoto 1975, Wolf 1988).

IPNV is the prototype virus of the family Birnaviridae, characterised by 2 linear genomic segments of doublestranded RNA (Dobos 1976). The larger genomic segment, $\mathrm{A}$, has 2 open reading frames (ORF), of which the large ORF encodes a polyprotein with a protein order of $\mathrm{NH}_{2}$-pVP2-NS/VP4-VP3-COOH (Duncan \& Dobos 1986). The polyprotein is proteolytically selfcleaved by the non-structural (NS) protease, also named VP4 (Duncan et al. 1987, Petit et al. 2000); it is uncertain whether the protease activity functions in trans or is restricted to self-cleavage of the polyprotein (Magyar \& Dobos 1994a). This cleavage results in the 2 structural peptides pVP2 and VP3. pVP2 is further trimmed in its carboxy terminus to VP2 (Petit et al. 2000), which is a major component of the virus particle. The VP3 protein is considered to be an internal protein of the virus particle with RNA-binding properties (Hjalmarsson et al. 1999). The NS/VP4 was formerly thought to be present in infected cells only, and not to be part of the virus particle. However, both NS/VP4, as well as truncated forms of this protein, have been found in purified virus particles by immune precipitation and Western blotting (Magyar \& Dobos 1994b). 
Studies of birnavirus infection in chickens and immunisation of mammals with IPNV indicate that VP2 is the major protective antigen (Caswell-Reno et al. 1986, Fahey et al. 1989) and an important target for the humoral immune response in fishes (Yamamoto 1975). Although there are reports that some VP3-specific monoclonal antibodies (MAb) can neutralize the virus (Tarrab et al. 1993, Park 1996), the majority of neutralising MAbs are VP2-specific (Frost et al. 1995, Heppell et al. 1995, Tarrab et al. 1995). Epitope mapping has shown that neutralising MAbs primarily bind to the central third and partly to the C-terminal part of VP2, and the epitopes are of both continuous and discontinuous nature (Frost et al. 1995, Heppell et al. 1995, Tarrab et al. 1995). Serotyping using polyclonal antibodies is also based on differences of conformational dependent epitopes being mapped to the variable central part of VP2 (Liao \& Dobos 1995).

Non-symptomatic IPNV carrier fishes may have circulating neutralising antibodies (Yamamoto 1975, Ahne \& Thomsen 1986), indicating that the humoral immune response alone is not capable of clearing the infection. A goal for an efficient IPN vaccine would consequently be stimulation of both the humoral and cellular responses. Commercially available IPN vaccines for the salmon industry are presently based on either inactivated cell culture-propagated virus, or Escherichia coli-expressed structural virus proteins such as immunogens (Christie 1997). However, despite the current possible vaccination, IPN still is a problem for the Atlantic salmon farming industry.

In the present work, the initial steps in the development of a DNA vaccine against IPN is described. The plasmids that were constructed were shown to express proteins both in cell cultures as well as in vivo. We injected 5 different combinations of plasmids expressing IPNV proteins into postsmolts of Atlantic salmon in an experimental challenge assay for IPN. One of the vaccinated fish group was highly protected compared to the other vaccinated groups and control groups.

\section{MATERIALS AND METHODS}

Cells and virus. The bluegill Lepomis macrochirus fry and Chinook salmon Oncorhynchus tschawytscha embryo cell lines BF2 and CHSE-214 were used for the propagation of IPNV as well as for transfection studies. The cells were cultivated at $20^{\circ} \mathrm{C}$ in Eagle's minimum essential medium (EMEM) with Earle's salts and supplemented with $10 \%$ fetal calf serum (FCS), $2 \mathrm{mM}$ L-glutamine, $2 \% \mathrm{NaHCO}_{3}$ and $0.5 \%$ penicillin/streptomycin at $20^{\circ} \mathrm{C}$. When virus was propagated, $15^{\circ} \mathrm{C}$ and $2 \%$ FCS were used.
The IPNV isolate ('Rauma') was used for the plasmid constructs. It was originally isolated from a naturally occuring IPN outbreak in farmed Atlantic salmon in 1988, and represents a virulent isolate (kindly donated by Dr. J. Krogsrud). It has less than 5 passages in cell culture and belongs to the Sp serotype, which is the only IPNV serotype that has been found in IPN outbreaks in Norwegian salmon aquaculture.

Plasmid constructions. Total RNA was extracted from IPNV-infected BF2 cells and was used in a $20 \mu \mathrm{l}$ reverse transcription reaction. The resultant cDNA was used as template for PCR amplifications performed with HindIII and BamHI 5'-tailed primers. The following parts of the IPNV genome were amplified: (1) the polyprotein gene (Bases131-3046; numbers refer to GenBank D00701); (2) VP2 gene (131-1554); (3) N-terminal part of VP2 (131-753); (4) central part of VP2 (521-1183); (5) C-terminal part of VP2 (573-1554); (6) VP3 (2231-3046). The DNA fragments obtained by PCR were cloned into the $\mathrm{pCR}^{\circledR} 2.1$-TOPO vector by TOPO TA cloning ${ }^{\circledR}$ (Invitrogen). The cloned DNA fragments were subsequently subcloned into HindIII/ BamHI sites in the plasmid vector pEGFP-N1 (Clontech Laboratories), a shuttle vector in which the cytomegalovirus (CMV) immediate early promoter controls the expression of the cloned gene. The cloned genes were expressed as fusions to the N-terminus of a variant of green fluorescent protein (EGFP). The plasmids constructed were named pEGFP-N1-SegA, pEGFPN1-VP2, pEGFP-N1-VP2a, pEGFP-N1-VP2b, pEGFPN1-VP2c and pEGFP-N1-VP3, respectively.

The VP2 gene was also amplified with primers with HindIII and NotI 5'-tails and cloned inbetween the HindIII site in the multiple cloning site and the Not I site that follows the EGFP sequence of the pEGFP-N1 vector. The subsequent plasmid, called pN1-VP2, was thus without the EGFP gene and expressed VP2 without any fusion partner. The plasmids were purified using Qiagen plasmid kits (Qiagen) prior to further experiments. The nucleotide sequences of the cloned genes, polyprotein, VP2, VP2 fragments and VP3 in pEGFP-N1, were sequenced (ABI Prism 377, Perkin Elmer Applied Biosystems). The nucleotide and amino acid sequences were aligned using the nucleotideBLAST (Altschul et al. 1997), Clustal W (Thompson et al. 1994) (Vector NTI, InforMax) and PSORT II (Human Genome Centre, Institute for Medical Science, University of Tokyo) programmes.

Protein expression in cell culture. The ability of the constructed plasmids to express IPNV proteins in fish cells was tested by transfection of BF2 and/or CHSE214 cells. The cells were seeded in 96-well plates at $50 \%$ confluency and transfected the following day with the plasmid in FuGENE ${ }^{\mathrm{TM}} 6$ transfection reagent (Roche). Briefly, $6 \mu \mathrm{l}$ FuGENE was added to $94 \mu \mathrm{l}$ 
EMEM and incubated for $5 \mathrm{~min}$ at room temperature, then $1 \mu \mathrm{g}$ of purified plasmid was added and further incubated for $15 \mathrm{~min}$ at room temperature. From this mixture, $5 \mu \mathrm{l}$ was added to each well and expression of EGFP fused proteins was assessed by UV-microscopy at $3 \mathrm{~d}$ post-transfection.

Immunocytochemical staining using IPNV-specific MAbs was also performed. Transfected cells were fixed in methanol:acetone 1:1 for $2 \mathrm{~min}$ at room temperature, washed with phosphate-buffered saline (PBS), incubated with $0.3 \% \mathrm{H}_{2} \mathrm{O}_{2}$ for $30 \mathrm{~min}$, washed with PBS and blocked with $5 \%$ BSA in PBS for $60 \mathrm{~min}$. The MAbs that were used were the VP2-specific AS1 and VP3-specific E5 (Caswell-Reno et al. 1986) (DiagXotics); these MAbs were preferred as they performed better than a polyclonal IPNV serum in staining IPNV-infected cells. The MAbs were incubated overnight at $4^{\circ} \mathrm{C}$ in PBS with $2.5 \%$ BSA. Expressed proteins from $p E G F P-N 1-S e g A, p E G F P-N 1-V P 2$ and pEGFP-N1-VP2a，pEGFP-N1-VP2b，pEGFP-N1-VP2c and pN1-VP2 were tested with AS1, while pEGFP-N1VP3 was tested with E5. Secondary antibody was biotin-conjugated sheep anti-mouse (Amersham Pharmacia) using 45 min incubation at room temperature in PBS with $2.5 \%$ BSA. Then incubation for 30 min with streptavidin-peroxidase complexes (DAKO Glostrup) followed. SIGMA FAST ${ }^{\mathrm{TM}}$ DAB (3,3'-diaminobenzidine) (Sigma) was used as substrate.

Delivery and expression of fusion vectors in vivo. Transient-expression studies were performed by microinjection in zebrafish embryos with the plasmids pEGFP-N1-SegA, pEGFP-N1-VP2, and pEGFP-N1-VP3. Gene-Gun $^{\mathrm{TM}}$ (Bio-Rad)-mediated transfer and intramuscular injection of pEGFP-N1-VP2 were performed in adult zebrafish. The $\mathrm{pEGFP-N1}$ vector was included as positive control.

In zebrafish embryos, the plasmids were microinjected as previously described (Collas et al. 1997) and expression was monitored using an Olympus BX 60 microscope (Olympus), equipped with NIBA filter, F-view CCD camera and SIS software (Soft Imaging System).

Cartridges for gene gun-mediated DNA transfer were prepared as previously described (Torgersen 2000), using $1 \mu \mathrm{m}$ microcarriers and $1 \mu \mathrm{g}$ plasmid DNA per dose. Briefly, plasmid DNA was slowly added drop-wise to a uniform suspension of microcarriers containing $50 \mathrm{mM}$ spermidine and precipitated onto the microcarriers by addition of $1 \mathrm{M} \mathrm{CaCl}_{2}$. Successive ethanol and centrifugation steps dehydrated the microcarrier suspension, until a uniform suspension free of aggregates was obtained. The pellet was resuspended in $100 \%$ ethanol and $0.1 \mathrm{mg} \mathrm{ml}^{-1}$ polyvinylpyrrolidone (PVP) and coated to the inner surface of a gold coat tubing. The plasmid DNA was transferred using 200 psi pressure, and GFP activity was monitored on epidermal samples removed $24 \mathrm{~h}$ post-delivery.

In addition, epidermal/dermal biopsies were homogenized in $200 \mu \mathrm{l}$ buffer (1mM DTT, $1 \%$ Triton X100, $10 \mathrm{mg} \mathrm{ml}^{-1}$ aproteinein, leupeptin and pepstatin in PBS). After heat denaturation and centrifugation at $14000 \times g$ for $2 \mathrm{~min}, 50 \mu \mathrm{l}$ of the supernatants were run on $10 \%$ SDS-PAGE and subsequently electroblotted to a nitrocellulose membrane. The membrane was washed twice in $1 \times$ Tris-buffered saline (TBS) for 10 min before overnight blocking with $10 \%$ horse serum in $1 \times$ TBS. After twice washing in $1 \times$ TBS-T for 10 min, a GFP MAb ( $\alpha$ GFP 8362-1, Clontech) in TBS-T with $10 \%$ horse serum was added and incubated for $90 \mathrm{~min}$ at room temperature. Similar washing and incubation conditions were used for secondary antibody, horseradish-conjugated rabbit anti-mouse (Sigma). For development, $10 \mathrm{ml} 50 \mathrm{mM}$ Tris, pH 7.6, and $400 \mu \mathrm{l} 0.01 \mathrm{mg} \mathrm{ml}^{-1}$ 4-CIN (4-chloro-1-naphthol; Sigma) were mixed and filtered before addition of $10 \mu \mathrm{l} 30 \% \mathrm{H}_{2} \mathrm{O}_{2}$.

Intramuscular injections in adult zebrafish consisted of $1 \mu \mathrm{g} \mathrm{ll}^{-1}$ plasmid DNA in PBS with $0.5 \%$ phenol red. The fish were anesthetized with $0.05 \%$ Tricaine, and $5 \mu \mathrm{l}$ plasmid DNA solution was injected to the lateral line using a $29 \mathrm{G}$ needle. To minimize loss of injected material, the needle was held in place for $3 \mathrm{~s}$ after injection. Biopsies were sampled with tweezers after removing the skin, homogenized, and analysed by Western blotting as described for epidermal samples.

Experimental challenge. The challenge experiment was performed at the Norwegian Institute of Fisheries and Aquaculture research station in Tromsø, Norway. The experimental design has been described elsewhere (Johansen \& Sommer 2001). Briefly, Atlantic salmon postsmolts of the NLA strain with an average size of approximately $20 \mathrm{~g}$ were injected intramuscularly. In a small preliminary experiment, indications of protection were observed for fish given $15 \mu \mathrm{g}$ of each plasmid pEGFP-N1-SegA and pEGFP-N1-VP2, and this set-up was therefore repeated (Group 2). In the other groups, $25 \mu \mathrm{g}$ of each plasmid diluted in a total of $100 \mu \mathrm{l}$ PBS were given to ensure that the amount of administrated DNA would probably not be a limiting factor.

We used 3 replicates of 7 groups, each group consisting of 50 fish. In addition, to survey possible mortality due to causes other than IPN, 200 fish were kept in a separate tank. No mortality was recorded in this tank. From each of the 7 groups, 1 replicate, i.e. 350 fish, was kept together in a separate tank. The plasmid constructions administrated to each group are shown in Table 1 . The fish were tagged by tattooing $(2 \%$ alcian blue, Panjet inoculator) at vaccination. 
Table 1. Composition of injected plasmids administrated to each group. Group 1: negative control, i.e. received plasmid without insert; Group 2: fish in this group were given $15 \mu \mathrm{g}$ of each plasmid; Group 7: this group did not receive any plasmid and was thus a control of the challenge model

\begin{tabular}{|c|c|c|c|c|c|c|c|c|}
\hline Group & $\begin{array}{c}\text { pEGFP- } \\
\text { N1 }\end{array}$ & $\begin{array}{c}\text { pEGFP- } \\
\text { N1-SegA }\end{array}$ & $\begin{array}{l}\text { pEGFP- } \\
\text { N1-VP2 }\end{array}$ & $\begin{array}{l}\text { pN1- } \\
\text { VP2 }\end{array}$ & $\begin{array}{l}\text { pEGFP- } \\
\text { N1-VP2a }\end{array}$ & $\begin{array}{c}\text { pEGFP- } \\
\text { N1-VP2b }\end{array}$ & $\begin{array}{l}\text { pEGFP- } \\
\text { N1-VP2c }\end{array}$ & $\begin{array}{l}\text { pEGFP- } \\
\text { N1-VP3 }\end{array}$ \\
\hline 1 & + & & & & & & & \\
\hline 2 & & + & + & & & & & \\
\hline 3 & & & & & + & + & + & + \\
\hline 4 & & & & + & & & & \\
\hline 5 & & & & & + & + & + & \\
\hline 6 & & & & & & + & & \\
\hline 7 & & & & & & & & \\
\hline
\end{tabular}

To test for non-symptomatic persistent IPNV carriers, kidney samples from 10 fish were tested for the presence of IPNV at vaccination and similarly at challenge, by inoculation, of kidney samples on CHSE cells. After $7 \mathrm{~d}$ incubation the cell layers were studied for cytopathic effect of kidney sample inoculation. The samples were passed twice. All samples were found to be IPNV-negative.

At the onset of the experiment, the fish were kept in freshwater. At the start of the week of vaccination, a smoltification-regime was carried out, making it possible to transfer the fish to saltwater prior to challenge. The success of the smoltification regime was evaluated by analysing blood samples for plasma chloride. The fish were kept at $10^{\circ} \mathrm{C}$, and 686 degree-days postvaccination they were challenged with IPNV (Johansen \& Sommer 2001). The average size of the fish was then approximately $60 \mathrm{~g}$. A virus suspension containing IPNV serotype $\mathrm{Sp}$, Isolate $\mathrm{CD}$, was added to the tank water, ensuring a homogenous spread in each experimental tank. The Isolate CD used by Norwegian Institute of Fisheries and Aquaculture Research station for the challenge experiment was not available as gene donor for the plasmid constructions, and its gene sequence was not known. Autopsy of dead fish collected from all 3 tanks during the challenge showed gross pathological changes in accordance with IPNVinduced disease, including petecchial bleedings in the interpyloric tissue, dark liver and anaemia. In addition, samples from the head kidney were positive for IPNV, as found after inoculation on CHSE cells, and negative for bacteria, as found after seeding on blood agar plates, as described elsewhere (Johansen \& Sommer 2001). Mortalities in the challenged groups were recorded daily until termination of the experiment at 40 d post-vaccination.

The relative percent survival (RPS) was calculated as (1 - cumulative mortality vaccinated group/cumulative mortality non-vaccinated group) $\times 100$. A chi-square test was used for statistical analysis of the groups.

\section{RESULTS}

\section{Nucleotide sequence alignments}

The nucleotide sequence alignments confirmed a close homology of the Rauma isolate to the Sp serotype of IPNV, with $99.1 \%$ identity to the N1 isolate (GenBank D00701) in the VP2 gene. (The N1 isolate was the first IPNV from Norwegian salmon aquaculture that had its gene sequence determined, and is thus often used as a geographical prototype strain.)

\section{Expression of fusion proteins in fish cell lines}

For all plasmid constructions, the expression of the fused IPN-EGFP-specific proteins in transfected cell cultures was detected as fluorescent signals in cells (Fig. 1A-C). The subcellular locations varied for the different fusion proteins, as observed visually. The pEGFP-N1-SegA, pEGFP-N1-VP2, and pEGFP-N1VP2a-expressed fusion proteins were found in both the nucleus and cytoplasm. Perinuclear inclusions were frequently seen for the pEGFP-N1-VP2-expressed protein. Proteins expressed by the pEGFP-N1-VP3, pEGFP-N1-VP2b and pEGFP-N1-VP2c were present only in the cytoplasm, the latter mainly perinuclearly. The efficiency of the transfection-protein expression assay, as evaluated by the number of fluorescent cells and visual fluorescence intensity of parallel transfections, indicated that the pEGFP-N1-VP2, pEGFP-N1VP2a, pEGFP-N1-VP2b and pEGFP-N1-VP3 plasmids produced the most abundant expression, while the pEGFP-N1-VP2c and pEGFP-N1-SegA plasmids yielded the least.

Specific identification of the IPNV parts of the fusion protein expressed by the pEGFP-N1-SegA was achieved by immunocytochemical staining with the VP2-specific MAb AS1, although the colouration was weak (data not shown). The pEGFP-N1-VP3- 
expressed peptide stained with the MAb E5 (Fig. 1D). The staining was seen as a distinct brown colour in the same subcellular compartments as visible in fluorescent microscopy. None of the pEGFPN1-VP2a, pEGFP-N1-VP2b, pEGFP-N1-VP2c, pEGFPN1-VP2 and pN1-VP2-expressed VP2 polypeptide fragments were detectable with the VP2-specific MAb AS1.

\section{Expression of fusion proteins in zebrafish model}

Fluorescence microscopy of zebrafish larvae injected with pEGFP-N1-SegA, pEGFP-N1-VP2 and pEGFPN1-VP3 and of epidermal samples from adult zebrafish after gene gun-mediated pEGFP-N1-VP2 transfer all demonstrated strong fluorescence, thus indicating both expression and retained fluorescence activity of the fusion peptides (Fig. 2). No particular organ distribution of the expression was seen in larvae.

Western blotting subsequent to administration of pEGFP-N1-VP2 from both epidermal samples after gene gun-mediated transfer and biopsies from intramuscularly injected adult fish revealed staining of a protein with a molecular weight of $85 \mathrm{kDa}$, which corresponds well with the calculated size of the VP2 and EGFP fusion protein (VP2: $54 \mathrm{kDa}+$ EGFP: 27 kDa) (Fig. 3).

\section{Experimental challenge}

Cumulative mortality of $33.6 \%$ was found in the challenge model control group (Group 7), i.e. the group that was not given any plasmid construction. The cumulative mortality in Group 1, which received constructions without insert, was $33.3 \%$, and thus almost identical to the challenge-model control. The cumulative mortality for Group 2 differed significantly ( $\mathrm{p}<0.0001$ ) from the cumulative mortality of the non-vaccinated control Group 7 (Table 2). Compared to Group 7, mortalities were also significantly lower for Group $4(\mathrm{p}=0.0165)$ and significantly higher for Group $6(\mathrm{p}=0.0494)$. However, Group 2, which was given pEGFP-N1-SegA and pEGFP-N1VP2, performed remarkably better than the other groups, with a cumulative mortality of $5.4 \%$, giving an RPS of 84. Group 4, which was given pN1-VP2, had the second lowest cumulative mortality, $24 \%$, and an RPS of 29 .
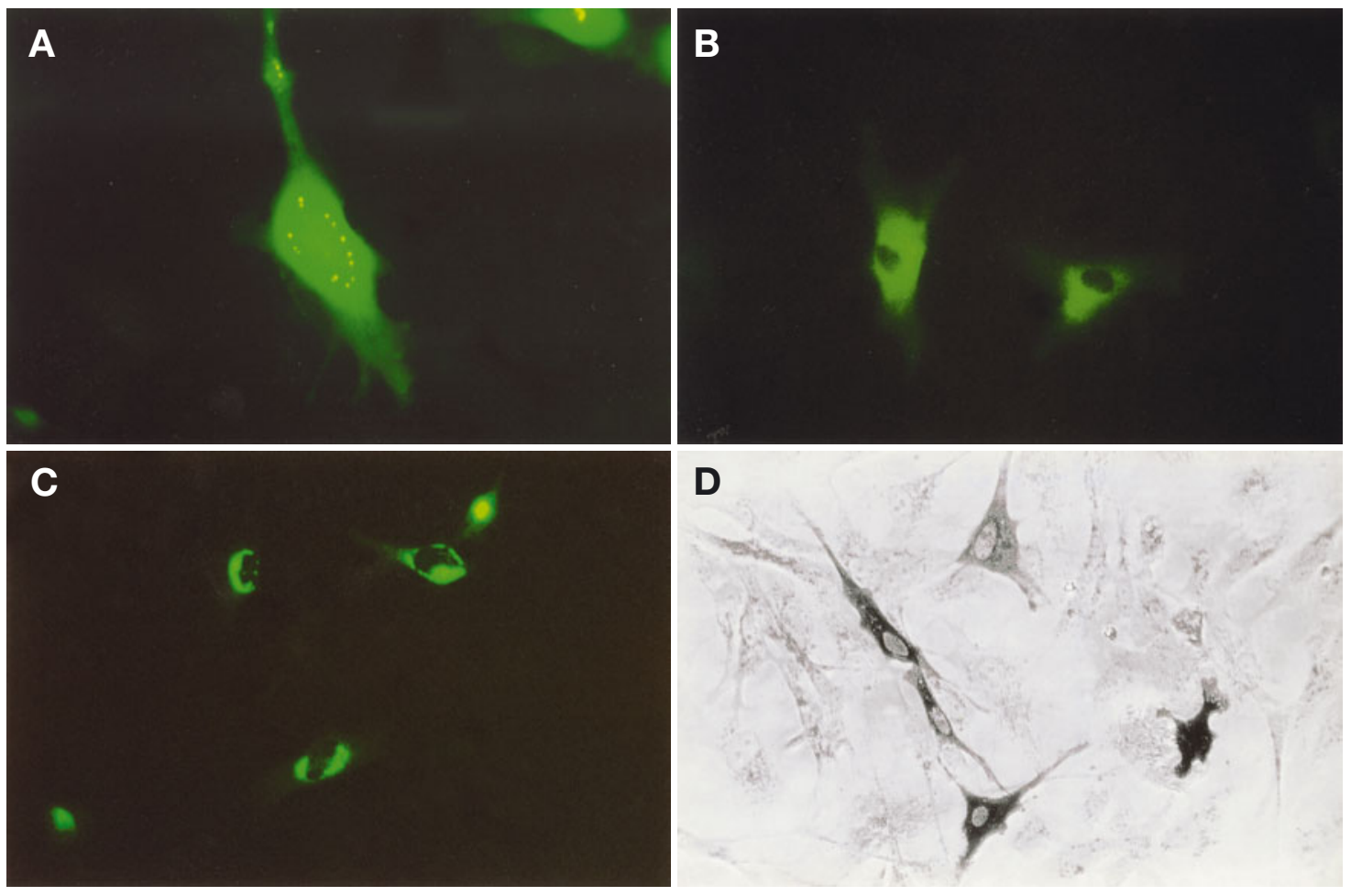

Fig. 1. Expression of (A) pEGFP-N1-VP2 in BF2 cells and of (B) pEGFP-N1-VP2b and (C) pEGFP-N1-VP2c in CHSE cells 4 d posttransfection; VP2 fusion protein is visible in both nucleus and cytoplasm, and perinuclear inclusions are also present. VP2b and VP2c are present in cytoplasm, with the VP2c mainly perinuclearly. (D) pEGFP-N1-VP3-expressed peptide in CHSE cells $4 \mathrm{~d}$ post-transfection stained with VP3-specific MAb E5 


\section{pEGFP-N1-VP2}
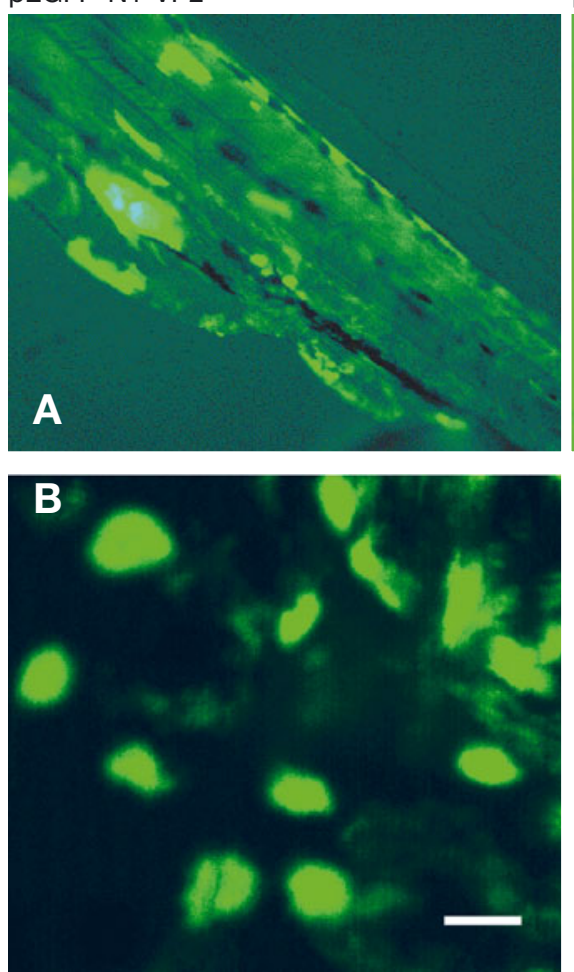

pEGFP-N1-VP3

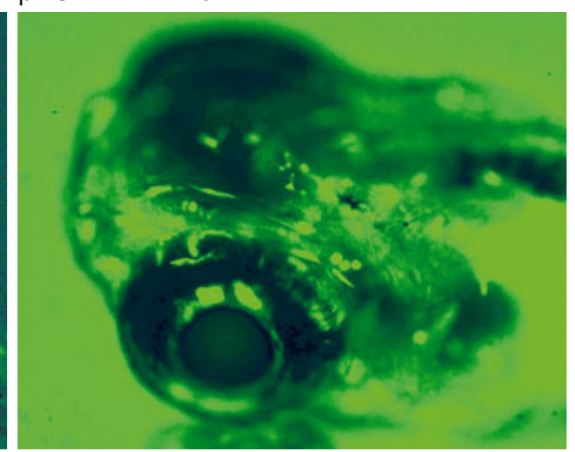

pEGFP-N1-SegA

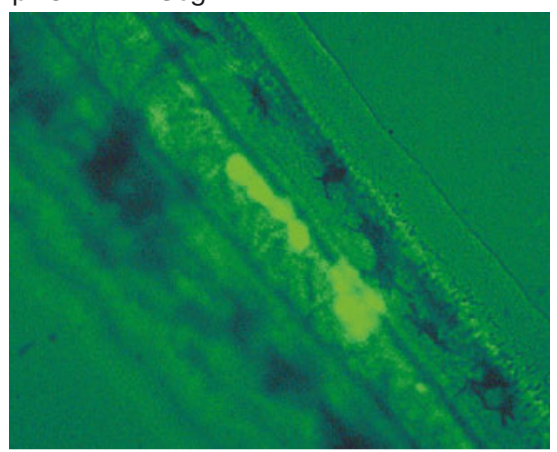

Fig. 2. Expression of (A) pEGFP-N1-VP2, pEGFP-N1-VP3, and pEGFP-N1-SegA in zebrafish larvae and (B) pEGFP-N1-VP2 in epidermal cells $24 \mathrm{~h}$ after gene gunmediated delivery to adult zebrafish. Scale bar in $\mathrm{B}=5 \mu \mathrm{m}$

\section{DISCUSSION}

The results of the experimental challenge showed that the cumulative mortalities in the control groups, i.e. 1 and 7 , were 33.3 and $33.6 \%$, respectively. The almost identical mortality of these 2 groups indicated that the effect of the challenge was evenly distributed. The relatively low death rate, i.e. with one-third of the control fish succumbing, could be an effect of the size of the fish at challenge, i.e. of their being less susceptible to IPN than fry, and demonstrates the difficulty with an IPN-challenge model using this size of fish, of obtaining a death rate of $70 \%$ - as would be preferable for vaccine testing. However, the results of succcessful cohabitation experiments obtaining high IPN mortality in Atlantic salmon smolts have recently been published (Bowden et al. 2002). A low death rate also requires a rather large number of experimental fish to obtain statistical significant differences. A good protection against the IPNV challenge was thus obtained for Group 2, i.e. pEGFP-N1-SegA and pEGFP-N1VP2-vaccinated fish, with an RPS of 84. The protection was similar in each of 3 replicate tanks. Although no other groups were given any of the subunits of the Group 2 vaccine, Group 4, which was injected with pN1-VP2, had an RPS of 29, indicating that the VP2 part was at least partly responsible for the induced protection seen in Group 2. The difference in protection between Groups 2 and 4 could be due to a potential positive protective effect of the EGFP fusion partner, as this was present in Group 2 peptides but not in Group 4 peptides. However, this is unlikely, as there was no difference in protection between Group 1, injected with pEGFP-N1, and Group 7, the unvaccinated control group. However, a coincident unmasking of epitopes by the EGFP fusion partner and thus an

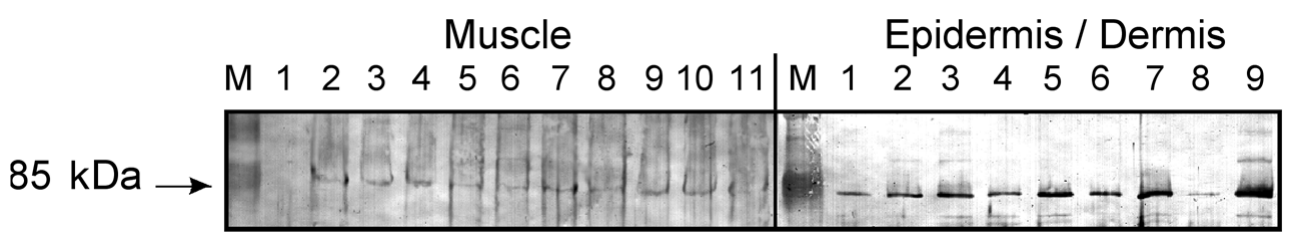

Fig. 3. Western blots using GFP-specific MAb. Samples were collected from 2 groups, each consisting of 10 zebrafish, injected intramuscularly (Muscle) or by gene gun administration (Epidermis and Dermis) with pEGFP-N1-VP2. Staining of a 85 kD protein, corresponding to the VP2-EGFP fusion protein, can be seen in all but the negative control (Lane 1, Muscle). Bio-Rad kaleidoscope prestained standard was used as molecular weight marker (M) 
Table 2. Cumulative mortality (\%) of the different groups. RPS: relative percent survival; na: not applicable (controls)

\begin{tabular}{|lrrrrc|}
\hline \multirow{2}{*}{ Group } & \multicolumn{4}{c}{ Cumulative mortality (\%) } & RPS \\
& Tank 1 & Tank 2 & Tank 3 & $\begin{array}{c}\text { Summary } \\
\text { Tanks 1-3 }\end{array}$ & \\
& & & & & \\
\hline 1 & 44.0 & 30.0 & 26.0 & 33.3 & na \\
2 & 6.0 & 6.0 & 4.1 & 5.4 & 84 \\
3 & 33.3 & 40.0 & 42.0 & 38.4 & -14 \\
4 & 26.5 & 21.6 & 24.0 & 24.0 & 29 \\
5 & 39.2 & 24.5 & 24.5 & 29.4 & 12.5 \\
6 & 50.0 & 27.9 & 44.0 & 40.6 & -21 \\
7 & 38.0 & 28.3 & 34.6 & 33.6 & na \\
\hline
\end{tabular}

immune stimulating effect cannot be ruled out. The major difference between Group 2 and 4 vaccines was the pEGFP-NI-SegA component of the Group 2 vaccine. This may imply that the difference in protection between these groups was caused by NS/VP4 posttranslational proteolytic cleavage of the polypeptide. Theoretically, the products of proteolysis could be better inducers of protective immunity, as a consequence of cellular processing of the proteolytic products compared to VP2/VP3 derived directly from expression plasmids. In our study, discontinuous epitopes were preserved in pEGFP-N1-SegA expression of the VP2, as the conformational-dependent, multi serotype neutralising MAb AS1 recognized pEGFPN1-SegA but not pN1-VP2 and pEGFP-N1-VP2expressed peptides. Important immunogenic properties of expressed VP2 were thus retained by pEGFP-N1-SegA. The AS1 MAb neutralizes all but one, A4 Hecht, of the IPNV serotypes, but does not bind to denatured virus particles or Escherichia coliexpressed VP2 in dot-blots (Frost et al. 1995). This indicates that the AS1-binding epitope is conserved after posttranslational processing of the pEGFP-N1-SegA as opposed to prokaryotic expression.

In our system, the expressed VP2 extended from Positions 1 to 474 of the polyprotein, based on an approximation of the minimum size of VP2 (Havarstein et al. 1990). However, recently, the pVP2-NS/VP4 cleavage site has been mapped to occur between Residues 508 and 509 of the Sp serotype (Petit et al. 2000). Further, carboxy terminal cleavage by NS/VP4 or cellular proteases of pVP2 occurs at 495-496 and/or 486-487, creating VP2 (Petit et al. 2000). Compared to this, the pN1-VP2 and pEGFP-N1-VP2-encoded VP2 products were truncated by 12 carboxy terminal residues. A crucial role of this carboxy terminus of VP2 in immune protection cannot be ruled out, but prokaryotic expressed recombinant VP2 with even further carboxy terminal truncation, encompassing Residues 1 to 453, induced a virus-suppressive response after vaccination (Frost \& Ness 1997). This indicates that the truncation of VP2 in our system does not necessarily diminish immune protection.

Another possibility may be that the immune response against the NS/VP4 part of the polyprotein is important in protection. This IPNV protein was only expressed by plasmids of Group 2. Although it has previously been found that virus-specific proteolytic activity could not be inhibited by IPNV-specific antisera, this could suggest lack of anti-NS/VP4 antibodies in the antiserum used due to the fact that NS/VP4 is not a part of the virus particles used as immunogens in antiserum production (Manning et al. 1990).

Fish in Group 2 were injected with $15 \mu \mathrm{g}$ of each plasmid, while fish in the other groups received $25 \mu \mathrm{g}$ of each plasmid. In another study, higher expression of luciferase in rainbow trout after administration of $50 \mu \mathrm{g}$ of plasmid compared to 10 and $25 \mu \mathrm{g}$ was found (Anderson et al. 1996b), implying that the large amount of plasmids used in our experiments did not have a detrimental effect on the expression. On the other hand, protective effect against viral hemorrhagic septicaemia has been obtained with as little as $0.01 \mu \mathrm{g}$ plasmid product (Lorenzen et al. 2000).

Each of the plasmids used in Group 5 encoded fragments of the VP2 peptide. Together, these plasmids expressed all amino acids of the VP2 with large overlaps. The cumulative mortality in this group was not statistically significant different from the control groups. In Group 3, VP3-encoding plasmid was added to the plasmids used in Group 5; this did not enhance protection, but reduced the RPS even further, i.e. -14 for the unvaccinated control group; but again this was not statistically significant different from control groups. The MAb E5 demonstrated the specificity of the VP3encoded product. And finally, Group 6, injected with plasmid pEGFP-N1-VP2b, encoding the central part of VP2 including hypervariable parts, performed the worst, with an RPS of -21 . These results were unexpected. Although there are several variable regions within the large ORF of genomic Segment A of IPNV (Blake et al. 2001), the central variable domain of the VP2 peptide from Positions 183 to 335 encompasses 2 hydrophilic hypervariable regions (Heppell et al. 1995).

Furthermore, previous expression studies of deletion fragments of VP2 have demonstrated that both the region determining serotype properties and the binding sites for several neutralizing MAbs that either recognize continuous or discontinuous epitopes, are localized within the central part of VP2 and the 20 adjacent amino acids of the conserved C-terminal part (Frost et al. 1995, Heppell et al. 1995, Liao \& Dobos 1995). These results suggest that the central part of VP2 is most important in inducing a protective humoral immune response, and the pEGFP-N1-VP2b, which encodes 
Positions 130 to 350, was constructed accordingly. However, our results after challenge of fish injected with plasmids encoding truncated forms of VP2 did not induce protection. Possible reasons for this may include: (1) the VP2 fragments may have lost discontinuous epitopes, as indicated by the loss of binding of the MAb AS1; (2) continuous epitopes binding neutralizing MAbs do not induce protective response in salmon in vivo; (3) elements other than the humoral response are more important for protection after DNA vaccination; (4) species differences.

In our study, all fusion peptides were expressed in both BF2 and CHSE-214 fish cell lines, as shown by green fluorescence from the EGFP moiety fused to the C-terminus of the IPNV-specific peptide. This indicates that the CMV promoter was active in these cells and that no toxic effects of the fused proteins were observed. This is in accordance with a previous study that showed higher expression in rainbow trout when the luciferase gene expression was controlled by the CMV promoter compared to different fish promoters (Anderson et al. 1996b). Furthermore, the in vivo expression of the plasmid constructs as seen in epidermal tissues and in larvae of zebra fish demonstrated the versatility of the CMV promoter to induce expression in different cell types. Western blots from both epidermal and muscular samples, after gene gunmediated transfer and intramuscular injection, respectively, of pEGFP-N1-VP2, demonstrated that full-length fusion proteins were produced and that both these vaccine-administrating methods were functional. In the cell lines, the amounts of expressed proteins (as visually judged by the intensity of the fluorescence) were highest for the EGFP-VP2 fragments and for EGFP-VP3. The EGFP-VP2b occurred both as intense inclusions as well as diffuse fluorescence in the cytoplasm, while EGFP-VP2c fragments occurred often as intense cytoplasmic inclusions. The EGFP-VP2 fragments and EGFP-VP3 were also the smallest peptides expressed. The granular perinuclear location of the pEGFP-N1-VP2c, and partly also for the pEGFP-N1VP2b-expressed peptides, corresponds to the perinuclear clustering of the VP2 found in IPNV infection of CHSE-214 cells 10 to $12 \mathrm{~h}$ post-infection (p.i.) (Bootland et al. 1986, Espinoza et al. 2000).

IPN is traditionally a disease in fry, and as injection in such small fish is unpractical, several attempts with immersion/bathing vaccines have been tried with limited or no success, both with live attenuated (Hill \& Dixon 1977, Dorson et al. 1978) and inactivated (Bootland et al. 1986) virus and with subunit vaccines (Manning \& Leong 1990). The latter study, although performed on a small scale, revealed that immersion vaccination of rainbow trout Oncorhynchus mykiss fry with Escherichia coli-expressed large ORF polypep- tides from the Sp serotype induced protection against challenge with the Buhl strain, which belongs to a different serotype of IPNV (Manning \& Leong 1990). Another study demonstrated higher levels of protection after injection of recombinant polyprotein, than with recombinant VP2 (Bootland et al. 1993). In contrast, other investigators have found that immersionvaccinated brook trout Salvelinus fontinalis fry using inactivated, purified virus were not protected against IPNV challenge, but rather that mortalities in vaccinated groups were higher than in the unvaccinated control group (Bootland et al. 1986), however further studies by these authors showed that killed IPNV vaccines could induce protection (Bootland et al. 1990). Thus it is difficult to reach any conclusions from the literature on IPN vaccine efficiency in fry, because of the large number of variables that can influence the results.

In mammals, many vaccines against viral diseases are based on live attenuated virus that induces a protective immune response. For environmental reasons, it may be difficult to get approval for the use of live attenuated vaccines to control viral diseases in fish farming, thus making DNA vaccines a possible option. However, the potential risk factors of DNA vaccination for the environment and consumers must be clarified. DNA vaccination offers the advantage of cellular expression of viral proteins without the risks involved with an infectious virus. Demonstrations of expression of foreign genes in fish tissue and subsequent development of prototypes for protective DNA vaccines against viral pathogens in salmonids have been promising (Hansen et al. 1991, Anderson et al. 1996a, Boudinot et al. 1998, Lorenzen et al. 1999, Traxler et al. 1999). Furthermore, administration of restricted parts of viral genomic sequences, i.e. those parts encoding peptides that can induce protective responses, would further minimise environmental exposure to viral products. For instance, for infectious haematopoietic necrosis and viral hemorrhagic septicemia viruses, it has been shown that the viral glycoprotein alone induces protective immunity when expressed in DNA vaccine constructs (Corbeil et al. 1999, Lorenzen et al. 2000). Induction of acquired immunity after administration of a DNA vaccine construction is further dependent on expression efficiency, target cells and cellular processing and presentation of expressed proteins.

In conclusion, the present study has demonstrated that protection against IPN in Atlantic salmon postsmolts can be achieved by DNA vaccination. It cannot, from our studies, be concluded which parts of the large ORF of genomic Segment A-encoded peptides induce protection. However, only that group of fish that received plasmids encoding all the large ORF polyprotein obtained good protection. 
Acknowledgements. This work was supported by grant no. 120043/122 from the Norwegian Research Council and by GenoMar asa, Oslo Research Park, Gaustadalléen 21, 0349 Oslo.

\section{LITERATURE CITED}

Ahne W, Thomsen I (1986) Infectious pancreatic necrosis: detection of virus and antibodies in rainbow trout IPNVcarrier (Salmo gairdneri). Zentbl Vetmed B 33:552-554

Altschul SF, Madden TL, Schaffer AA, Zhang J, Zhang Z, Miller W, Lipman DJ (1997) Gapped BLAST and PSIBLAST: a new generation of protein database search programs. Nucleic Acids Res 25:3389-3402

Anderson ED, Mourich DV, Fahrenkrug SC, LaPatra S, Shepherd J, Leong JA (1996a) Genetic immunization of rainbow trout (Oncorhynchus mykiss) against infectious hematopoietic necrosis virus. Mol Mar Biol Biotechnol 5: $114-122$

Anderson ED, Mourich DV, Leong JA (1996b) Gene expression in rainbow trout (Oncorhynchus mykiss) following intramuscular injection of DNA. Mol Mar Biol Biotechnol 5:105-113

Blake S, Ma JY, Caporale DA, Jairath S, Nicholson BL (2001) Phylogenetic relationships of aquatic birnaviruses based on deduced amino acid sequences of genome segment $\mathrm{A}$ cDNA. Dis Aquat Org 45:89-102

Bootland LM, Dobos P, Stevenson RM (1986) Experimental induction of the carrier state in yearling brook trout: a model challenge protocol for IPNV immunization. Vet Immunol Immunopathol 12:365-372

Bootland LM, Dobos P, Stevenson RMW (1990) Fry age and size effects on immersion immunization of brook trout, Salvelinus-fontinalis Mitchell, against infectious pancreatic necrosis virus. J Fish Dis 13:113-125

Bootland LM, Allen NM, Edwards K, Lorz HV, Virk L (1993) Efficacy of immunization of rainbow trout fry with recombinant vaccines against IPNV. Bull Aquac Assoc Can 93-4: 139-142

Boudinot P, Blanco M, De Kinkelin P, Benmansour A (1998) Combined DNA immunization with the glycoprotein gene of viral hemorrhagic septicemia virus and infectious hematopoietic necrosis virus induces double-specific protective immunity and nonspecific response in rainbow trout. Virology 249:297-306

Bowden TJ, Smail DA, Ellis AE (2002) Development of a reproducible infectious pancreatic necrosis virus challenge model for Atlantic salmon, Salmo salar L. J Fish Dis 25:555-563

Caswell-Reno P, Reno PW, Nicholson BL (1986) Monoclonal antibodies to infectious pancreatic necrosis virus: analysis of viral epitopes and comparison of different isolates. J Gen Virol 67:2193-2205

Christie KE (1997) Immunization with viral antigens: infectious pancreatic necrosis. Dev Biol Stand 90:191-199

Collas P, Husebye H, Aleström P (1997) Transferring foreign genes into zebrafish eggs by microinjection. In: Houdebine LM (ed) Transgenic animals-generation and use. Part II, Section D. Harwood Academic, Reading, p 119-122

Corbeil S, LaPatra SE, Anderson ED, Jones J, Vincent B, Hsu YL, Kurath G (1999) Evaluation of the protective immunogenicity of the N, P, M, NV and G proteins of infectious hematopoietic necrosis virus in rainbow trout Oncorhynchus mykiss using DNA vaccines. Dis Aquat Org 39:29-36

Dobos P (1976) Size and structure of the genome of infectious pancreatic necrosis virus. Nucleic Acids Res 3:1903-1924
Dorson M, Castric J, Torchy C (1978) Infectious pancreatic necrosis virus of salmonids-biological and antigenic features of a pathogenic strain and of a non-pathogenic variant selected in RTG-2 cells. J Fish Dis 1:309-320

Duncan R, Dobos P (1986) The nucleotide sequence of infectious pancreatic necrosis virus (IPNV) dsRNA segment A reveals one large ORF encoding a precursor polyprotein. Nucleic Acids Res 14:5934

Duncan R, Nagy E, Krell PJ, Dobos P (1987) Synthesis of the infectious pancreatic necrosis virus polyprotein, detection of a virus-encoded protease, and fine structure mapping of genome segment A coding regions. J Virol 61:3655-3664

Espinoza JC, Hjalmarsson A, Everitt E, Kuznar J (2000) Temporal and subcellular localization of infectious pancreatic necrosis virus structural proteins. Arch Virol 145:739-748

Fahey KJ, Erny K, Crooks J (1989) A conformational immunogen on VP-2 of infectious bursal disease virus that induces virus-neutralizing antibodies that passively protect chickens. J Gen Virol 70:1473-1481

Frantsi C, Savan M (1971) Infectious pancreatic necrosis virus - temperature and age factors in mortality. Wildl Dis 7:249-255

Frost P, Ness A (1997) Vaccination of Atlantic salmon with recombinant VP2 of infectious pancreatic necrosis virus (IPNV), added to a multivalent vaccine, suppresses viral replication following IPNV challenge. Fish Shellfish Immunol 7:609-619

Frost P, Havarstein LS, Lygren B, Stahl S, Endresen C, Christie KE (1995) Mapping of neutralization epitopes on infectious pancreatic necrosis viruses. J Gen Virol 76: $1165-1172$

Hansen E, Fernandes K, Goldspink G, Butterworth P, Umeda PK, Chang KC (1991) Strong expression of foreign genes following direct injection into fish muscle. FEBS Lett 290: $73-76$

Havarstein LS, Kalland KH, Christie KE, Endresen C (1990) Sequence of the large double-stranded RNA segment of the N1 strain of infectious pancreatic necrosis virus: a comparison with other Birnaviridae. J Gen Virol 71: 299-308

Heppell J, Tarrab E, Lecomte J, Berthiaume L, Arella M (1995) Strain variability and localization of important epitopes on the major structural protein (VP2) of infectious pancreatic necrosis virus. Virology 214:40-49

Hill BJ, Dixon PF (1977) Studies on IPN virulence and immunization. Bull Eur Assoc Fish Pathol 87:425-427

Hjalmarsson A, Carlemalm E, Everitt E (1999) Infectious pancreatic necrosis virus: identification of a VP3-containing ribonucleoprotein core structure and evidence for O-linked glycosylation of the capsid protein VP2. J Virol 73:3484-3490

Johansen LH, Sommer AI (2001) Infectious pancreatic necrosis virus infection in Atlantic salmon Salmo salar postsmolts affects the outcome of secondary infections with infectious salmon anaemia virus or Vibrio salmonicida. Dis Aquat Org 47:109-117

Liao L, Dobos P (1995) Mapping of a serotype specific epitope of the major capsid protein VP2 of infectious pancreatic necrosis virus. Virology 209:684-687

Lorenzen E, Einer-Jensen K, Martinussen T, LaPatra SE, Lorenzen N (2000) DNA vaccination of rainbow trout against viral hemorrhagic septicemia virus: a doseresponse and time-course study. J Aquat Anim Health 12: $167-180$

Lorenzen N, Lorenzen E, Einer-Jensen K, Heppell J, Davis HL (1999) Genetic vaccination of rainbow trout against viral haemorrhagic septicaemia virus: small amounts of plas- 
mid DNA protect against a heterologous serotype. Virus Res 63:19-25

Magyar G, Dobos P (1994a) Expression of infectious pancreatic necrosis virus polyprotein and VP1 in insect cells and the detection of the polyprotein in purified virus. Virology 198:437-445

Magyar G, Dobos P (1994b) Evidence for the detection of the infectious pancreatic necrosis virus polyprotein and the $17-\mathrm{kDa}$ polypeptide in infected cells and of the NS protease in purified virus. Virology 204:580-589

Manning DS, Leong JC (1990) Expression in Escherichia coli of the large genomic segment of infectious pancreatic necrosis virus. Virology 179:16-25

Manning DS, Mason CL, Leong JC (1990) Cell-free translational analysis of the processing of infectious pancreatic necrosis virus polyprotein. Virology 179:9-15

Park JWJGJ (1996) Identification of VP3 as an important neutralising epitope from DRT strain, a Korean isolate of infectious pancreatic necrosis virus (IPNV). Fish Shellfish Immunol 6:207-219

Petit S, Lejal N, Huet JC, Delmas B (2000) Active residues and viral substrate cleavage sites of the protease of the birnavirus infectious pancreatic necrosis virus. J Virol 74: 2057-2066

Tarrab E, Berthiaume L, Heppell J, Arella M, Lecomte J (1993) Antigenic characterization of serogroup 'A' of infectious pancreatic necrosis virus with three panels of monoclonal antibodies. J Gen Virol 74:2025-2030

Editorial responsibility: Jo-Ann Leong,

Kaneohe, Hawaii, USA
Tarrab E, Berthiaume L, Grothe S, O'Connor-McCourt M, Heppell J, Lecomte J (1995) Evidence of a major neutralizable conformational epitope region on VP2 of infectious pancreatic necrosis virus. J Gen Virol 76:551-558

Thompson JD, Higgins DG, Gibson TJ (1994) CLUSTAL W: improving the sensitivity of progressive multiple sequence alignment through sequence weighting, position-specific gap penalties and weight matrix choice. Nucleic Acids Res 22:4673-4680

Torgersen J, Collas P, Aleström P (2000) Gene-gun-mediated transfer of reporter genes to somatic zebrafish (Danio rerio) tissues. Marine Biotechnol 2:293-300

Traxler GS, Anderson E, LaPatra SE, Richard J, Shewmaker B, Kurath G (1999) Naked DNA vaccination of Atlantic salmon Salmo salar against IHNV. Dis Aquat Org 38: $183-190$

Wolf K (1988) Infectious pancreatic necrosis virus. In: Wolf K (ed) Fish viruses and fish viral diseases. Cornell University Press, Ithaca, NY, p 115-157

Wolf K, Snieszko SF, Dunbar CE, Pyle E (1960) Virus nature of infectious pancreatic necrosis in trout. Proc Soc Exp Biol Med 104:105-108

Wolf K, Quimby MC, Bradford AD (1963) Egg-associated transmission of IPN-virus of trouts. Virology 21:317-321

Yamamoto T (1975) Infectious pancreatic necrosis (IPN) virus carriers and antibody production in a population of rainbow trout (Salmo gairdneri). Can J Microbiol 21: 1343-1347

Submitted: March 24, 2003; Accepted: October 7, 2003

Proofs received from author(s): June 14, 2004 